\title{
Describing the Archive: Preservation of Space, Time and Discontinuity in Photographic Sequences
}

\author{
JANE BIRKIN, University of Southampton
}

\begin{abstract}
The important relationship between the material arrangement of the archive and its accompanying catalogue is discussed and rationalised from a position inside the institution, from where I argue that an understanding of physical and contextual relationships between interconnecting units is critical to the spatiotemporal understanding of the archived image. The archive catalogue list is determined by the original order of the archive material and is subsequently central to the maintenance of order, functioning as 'detector' and 'effector' (Hood and Margetts 2007). There is a consideration of the comparatively new concept of original order from its development in the late 1880s publication known as the 'Dutch Manual'. This manual for archivists emphasised recordkeeping without anticipating specific future use, a methodology that still persists today. The diachronic nature of archival ordering systems, dependant as it is on collection and use by original owners, is examined alongside important questions of narrativity and storytelling in photographic collections.
\end{abstract}

\section{KEYWORDS}

archive, description, list, narrative, photography, time

\section{The physical space of the archive}

The archive catalogue simultaneously describes and maintains the structures of order that are already present in a collection at the point of its arrival at the institution. The catalogue subsequently opens up an understanding of the context and temporality of the archive that is not always achievable through the examination of isolated archival objects fetched from strongrooms, or indeed from networks. In the case of the photographic image, a discrete form with a very short embodied time, the catalogue list becomes a critical tool in unlocking the temporality of the image through a multi- 
level spatial formation that matches that of the physical archive.

Catalogue and archive are usually two different media forms that are separately kept. However, Nina Lager Vestberg, in her critique of the Warburg and the Conway Libraries, describes how these collections (both of them relatively small and open access) are not fully catalogued and so rely on the physical storage as a finding aid: 'the filing cabinets and boxes are, at one and the same time, repositories for the 'things themselves' and catalogues explaining what things are' $(2013,476)$. She recognises that 'looking around and thinking with a physical archive can help you in a different sense to find it - that is, to realize and contextualize its significance in and as a broader set of findings' [original italics]. She argues that the archive, by virtue of the user's interaction with its arrangement, becomes a 'machine for thinking' (2013, 487). The Photographic Collection of the Warburg Library that Vestberg examines is a collection where objects are classified by keyword, according to Aby Warburg's theories on iconography, so considerable thinking has already materialised.

The material manifestation of catalogue happens in comprehensively catalogued and less semantically ordered archives too. The catalogue replicates the storage, often mentioning the physical traits of the storage system such as specific numbers of boxes and files and amount of the shelf space that the particular archive occupies. It defines for the reader the scope of the collection as it lays out, line by line, in list form, descriptions of objects, reflecting the physical relationships between discrete objects and between sets. Whilst it is primarily a record and a finding aid, the catalogue affords an imagining not only of the object itself, but of the organisation and the materiality of the hidden storage space - the visitor to this kind of archive rarely sees the physical arrangement of objects, except for perhaps an occasional glimpse of the box from which their requested files are temporarily removed. Once imagined, the archive, its structure, and the position of the single object relative to this structure, can be visualised, considered and more clearly understood. This mimics Vestberg's experiences in the Warburg photographic collection: interaction with objects and their arrangement through descriptions in the catalogue list allows an understanding of the complex spatiotemporal relationships between objects that would be otherwise impossible in a large archive. In this case, the catalogue itself becomes a compact and powerful machine for thinking.

The hierarchical arrangement of an archive materialises as a series of containers, in the physical space and the catalogue alike. This location-based arrangement starts with the building or institution itself, a place that is often loosely termed 'The Archive'. Placed inside this outer 'bricks and mortar' casing is a network of strongrooms and shelves. Here the archive object is placed in a folder; the folder within a box; the box stacked with associated boxes at a specified shelf location. The catalogue matches and describes this arrangement. Moving downwards within and from the holding institution, the catalogue structure continues with the name of the collection; then through cascading lists that might deal with groupings such as 
committees, people and events. These groupings are not imposed, but take their lead from the objects, as 'original order' is preserved. This is not a strict chronological or typological order, or an order of assumed importance, but the order in which the objects were accumulated or re-ordered through use: a diachronic or developmental ordering system. In some cases this could in fact be by time, type or importance, or a combination of all these things. The term 'original order' then relates to the order of the collection as it enters the archive and is perhaps better defined by the French term respect des fonds: the list of items in an archive respects and makes visible the actuality of order. The object itself (a photographic print, for example) may not be unique, but the list describes a unique place for this object amongst others; a unique context is defined.

Markus Krajewski $(2011,90)$ recounts how Melvil Dewey, who created the Dewey Decimal Classification system for books in 1876, calls for increased library efficiency through uniform cataloguing techniques of uniform materials. Archive materials are notably lacking in uniformity. As Judith Ellis $(1993,11)$ points out, libraries deal with 'consciously authored information products', and not with the rich, complex and variously kept records of a life or an organisation. Michel Foucault, in The Archaeology of Knowledge, defines the archive as 'that which determines that all these things do not accumulate endlessly in an amorphous mass, nor are they inscribed in an unbroken linearity' (2002, 145). The concept of original order for archives was developed in the late 1800s by Dutch archivists Muller and Van Riemsdijk, and authored as The Manual for Arrangement and Description of Archives (commonly known as The Dutch Manual) by Muller, Feith and Fruin in 1898. According to Eric Ketelaar, it was Van Riemsdijk who pioneered the approach of maintaining original order, as 'he tried to understand why and how records were created and used by their original users, rather than how they might be used in the future' (Ketelaar 1996, 33). The idea that one should not try to anticipate the specific future use of an object, but should allow for all possible uses, is fundamental to the practice of archival listing and description. The maintenance of original order (nonchronological, discontinuous) by the archivist allows for any amount of re-ordering and re-contextualisation by users, whilst freezing the complex temporal progression of the archive.

Deep inside the loose categories of the archive (loose because one continually finds difficult objects that defy categorisation) lies the description of the single item, although this concluding unit of description sometimes does not materialise at all, with information ending at folder level, or earlier. When it does appear, the objectlevel description varies in form and detail: the description of general papers might be just that, perhaps grouped only by a date range or a committee, whilst letters perceived to have historical significance could be fully transcribed. Images too are described with variable and unpredictable degrees of attention to detail, with a detailed object-level description of visual content being akin to the transcription of a letter. The multilevel description structure of the archive is defined by the 
International Council on Archives (ISAD(G) 2000, 11-12) as 'a hierarchical part-towhole relationship'. Its definition of 'item' as the 'smallest intellectually indivisible archival unit that can be described' is comparable to Foucault's definition of the 'statement' as an 'ultimate, undecomposable element that here can be isolated [...]. The atom of discourse' $(2002,90)$. Both these definitions exist in the context of seriality, and are concerned with part to whole relationships and shared functioning between parts. Foucault's views on seriality and groupings can be applied to the archive in the context of establishing knowledge from non-chronological and lacunose collections of archive objects, including image sets.

\section{Digital space}

Catalogue interfaces of digital archives can present themselves in various ways, but they broadly follow the same cascading container-based formula of folders and files as their physical counterparts; the terminology and the structure of the interface comes out of archival arrangement and returns back to it from the very differently ordered space of the network. The imagining and understanding of space and physicality through a catalogue interface prompted by the archive extends to other digital interfaces as well. Cornelia Vismann, in Files: Law, Media and Technology, recognises a nostalgia for tactile storage systems when she states, 'The very terminology of computer surfaces is designed to remind users seated before screens of the familiar world of files' $(2008,163)$. However, whilst user interfaces provided by institutions and even by photo-sharing sites might mimic archival storage systems, the networked storage of files is distinctly anarchival, and the term 'archive' that has become part of our digital vocabulary should be viewed as a metaphor, not as an indicator of the similarity of network storage to the actual storage systems of the archive.

Human memory is frequently compared to network storage and retrieval systems, but José Van Dijck explains how the library and archive were once used as metaphors to explain memory recall, as one 'searches through the stacks from which stored and unchanged information can be retrieved and read' $(2007,30)$. She goes on to describe how this paradigm was refuted by philosophers such as Henri Bergson, who argued in his work Matter and Memory (1896) that the brain does not store memory at all, but re-creates the past on demand. In this respect, as Van Dijck explains using new metaphors: 'the brain is less a reservoir than a telephone system' (2007, 30-31). In any case, there must be a distinction made between memory and understanding in the context of the storage of the archival object: memory is a living instrument and, like network storage, can be reconfigured at random; understanding is gained not through the mnemonic recall of a particular object, the status of which can change from one time to another, but through the fixed down spatial and contextual relationship that exists between objects. 
The arguments around digitisation, semantic reordering and de-contextualisation are now somewhat passé in the context of archive material, which is becoming absorbed into internet culture. Ernst $(2002,482)$ describes information on the Internet as 'quirky, transient and chaotically shelved', and this would seem to present a strong argument for preserving and documenting the ordered shelving systems of the physical archive, more than simply as a 'retro-outcome of digital culture' (Ernst 2001, 99), but as a platform that is vital for preserving anomalous spatial relationships and facilitating understanding and conceptual interpretation of historical documents and artefacts; as a back-up for the networked archive.

\section{Image description}

The object-level image description originates from a time before digital access. Today it is typically found within a catalogue list (printed and / or reproduced online) and separate from the image it describes, becoming redundant once the image is visible. It is written in prose, it is a description of the physicality and the visual content of the single image, and it is predominately context free. Contextual information is often stored at higher levels, where it brings information together. For example, describing a group of photographs means that the event that binds the series together is described, rather than individual visual elements and recognisable localised conditions. So whilst the group description reveals the broader event, the description of the single item tends to confirm a situation, a unique moment in time. Vilém Flusser uses the concepts of 'situation' and 'event' in his text 'Our Images': 'For the consciousness structured by images, reality is a situation: it imposes the relation between its elements. This consciousness is magical. For the consciousness structured by texts, reality is a becoming: it imposes the question of the event. This consciousness is historical' (2013 [1983], 93 [original italics]). Flusser is addressing the static nature of the image; it fixes a reality (a relationship between elements). He sees writing as a means to unfold the image, to temporalise and historicise it in relation to an event.

The description of a photograph is an inventory of visual information, a method of indexing and information management rather than hermeneutical analysis. The description writer is processing and presenting details without making judgments on their importance, and elements may be described in any order. In Parallel Texts, Victor Burgin $(2011,198)$, writing here about voice-over texts in his own practice, states, 'the material should be equally weighted and autonomously significant'. He places description in opposition to narrative, a position discussed in more detail later in this essay, as he continues:

This equality of status between elements has something analogous to 'description' in the classic distinction between description and narrative: the elements that make up a description may in principle be 
arranged in any order in time, whereas the elements that compose a narrative obey an invariable sequential order. (ibid. [original italics])

The archive image description must stand in for the image, and the researcher must judge if the photograph even needs to be seen: the description may deem the image irrelevant to the line of research, or the text itself might suffice. But description is a problematic and contradictory form that must be carefully managed: it uses dry, denoted, closed language, yet it may leave itself open to various interpretations. This presents a difficult problem for the archivist: the description must not preclude lines of research, but at the same time it should not trigger connotations that may weaken the image in terms of information and evidence. Images in the archive are not autonomous objects that carry their own language, the much-peddled 'universal language of photography' that is termed 'bourgeois folklore' by Allan Sekula (1982, 86). Sekula argues vigorously that meaning is not intrinsic to the photographic image and explains: 'it is clear that photographic meaning depends largely on context. [...] photographs, in themselves, are fragmentary and incomplete utterances. Meaning is always directed by layout, captions, text, and site and mode of presentation' (2003, 445-46). The visual, content-centred approach of archival description demands that images take their cultural and spatiotemporal context from their 'site and mode of presentation'; that is, from their surrounding objects and their meticulously recorded place in the archive catalogue.

\section{The order of the list}

Listing is a cultural technique that is employed regularly inside both personal and administrative milieux. In archive terminology, listing is the name for cataloguing: the making of a list or an inventory. It combines the administrative and the personal, as individual archivists, although guided by prescribed management rules and conventions of language, describe items differently. The cataloguing process involves the listing and numbering of every item in an archive, in the order in which it arrives into custodial care, whether in crates, carrier bags, sacks or other containers. Everything, to the last scrap of paper, is enumerable, and, when individually listed and numbered, is defined as a discrete unit with its own unique identifier. The list forms the catalogue interface, an interface made up of lists within lists. It is a contextualising force; a basic form of data visualisation that allows context to build. Robert E. Belknap endorses the twin archival notions of discrete object and part to whole relationships as he argues: 'Each unit in a list possesses an individual significance but also a specific meaning by virtue of its membership with other units' (2004, 15).

Christopher Hood and Helen Margetts use the language of cybernetics to define the dual use of administrative tools of government, such as the list: firstly 'detector', 'for taking in information'; and secondly 'effector', 'to try to make an impact on the world 
outside' (2007, 3). A list is an exceptionally convincing effector; it appears indexical and factual and this makes it an invaluable tool for government and a basic instrument of administrative power. Archives are built upon the structure of the list: they are organised by list and populated by many objects that fall into the broad category of list. Rolls, registers, accounts and inventories, many of them government and legal documents, are commonplace in archives. Vismann, who traces the list back to the Babylonian Empire, uses the term 'second writing scene' to describe listing, whilst at the same time recognising the power of this simple form to control and regulate, identifying the relationship between administrative writing and law (2008, 6). Archivists study law as part of their professional training, as they have to deal with issues of ownership and transfer of archives themselves, as well as those rights safeguarded through archives, such as property and land registers and other contractual documents.

Power is evident in records of the British colonies. Marlene Manoff $(2004,16)$ argues that 'the establishment and consolidation of the empire was built on the accumulation of information about people and places under colonial rule'. She goes on to describe how postcolonial scholars have needed to adopt strategies of reinterpretation and recontextualisation of information in order to 'call into question the colonial version of events' (ibid.). In other words, they turn the focus on the subjects of colonialism instead of the administrators, and examine the gaps in the records as much as the records themselves. The power is exerted in the initial production, collection and use of the records; their preservation inside the depository in original order allows power systems to be recognised and realignments to be made through the evidence of the paper trail. Wolfgang Ernst $(2002,482)$ acknowledges the power structures at work in military and scientific network technologies today and states: 'On the other side of the monitor [...] an authoritative archive of protocols is more rigidly at work than in any traditional national archive.' He suggests that perhaps we have more to fear from this new power base, one that leaves no paper trail (and only a limited data trail), than we ever did from state archives.

\section{Photography and list}

Ordinarily a list is understood to be made up of words or numbers (and in the case of the archive list both these are critical) but a list can also take the form of a photographic inventory, sharing with the written list many attributes and implications for the single item and the set. From early on, photography (and illustration before it) was assigned to scientific enquiry and subsequent classification, its indexical qualities making it a perfect medium for this. The exhibition Brought to Light: Photography and the Invisible, 1840-1900, at the San Francisco Museum of Modern Art in 2008, surveys a period when science and photography were in a state of rapid development and scientists were using cameras in conjunction with other optical devices. In the catalogue, Tom Gunning argues that these images functioned 'not simply to record a 
recognizable world, but also to provide images of a previously invisible one' (in Keller: 2008, 54). Jussi Parikka $(2012,21)$ discusses the emergence of 'the science of the image' and references scientist Robert Koch, who in his 'Zur Untersuchung von pathogenen Organismen', states that 'the photographic picture of a microscopic object can under certain circumstances be more important than [the object] itself'. These images demanded faith in the truth and accuracy of new technologies; a faith that was facilitated by the fact that the images fell under the umbrella of science, and were classified with a scientific rigour.

Anthropological investigation and archivisation was a field especially reinforced by photography. In his essay, 'The Body and the Archive,' Sekula, in the context of the early physiognomic applications of the photography of Alphonse Bertillon and Francis Galton, argues, 'The central artifact of this system is not the camera but the filing cabinet'; for Sekula it becomes 'a merger between optics and statistics.' He describes Bertillon's technique for criminal identification: 'First, he combined photographic portraiture, anthropometric description, and highly standardized and abbreviated written notes on a single fiche, or card. Second, he organized these cards within a comprehensive, statistically based filing system' (1986, 16-18). In his 1931 series, Menschen und Landschaften (People and Landscapes), August Sander used portrait photography to record and categorise people with what Sekula terms 'physiognomic empiricism' (1984, p.85). Sekula is sceptical of Sander's methodology and sees his scientific claims as an attempt to validate his artistic practice: 'I suspect Sander wanted to envelop his project in the legitimating aura of science without violating the aesthetic coherence and semantic ambiguity of the traditional portrait form.' (ibid.). In comparison to the technical and indexical sparsity of Bertillon's work with the human figure, Sander's pictures are beautifully lit, framed, dressed and posed: they look like art. Jens Jäger (2001, para. 3) suggests further tension between the social (aesthetic) and administrative functions of early photography, as commercial portrait photography, with its inherent respectability, was used to identify criminals until the 1890 s.

Creative photographic practice around classification, collection and typology has been defined over time by artists and photographers such as Sander, then, in the latter half of the twentieth century, Ed Ruscha and Bernd and Hilla Becher. On the work of the Bechers, Gregorio Magnani (1990, 81-82) remarks:

Meaning undergoes a circular series of displacements that transfer significance from a single image, to a comparison between similar images, to the overall project that brings the images together, to the conditions that produced the project as they are instanced in the individual images. It is only through their participation in a system of presentation, under the model of the archive, that the single images gain a significance which is larger than their particular instances. 
This is a consolidation of Belknap's statement that each item in the list gains 'specific meaning by virtue of its membership with other units' $(2004,15)$, a notion that is of fundamental importance to anyone working with typologically classified sets of images, whether scientific or artistic.

Margaret Iversen terms Ed Ruscha's seminal work of photographic seriality and categorisation, Twentysix Gasoline Stations (1963), as a performative piece, which she defines as, 'displacing spontaneity, self-expression and immediacy by putting into play repetition and the inherently iterative character of the instruction' $(2010,15)$. Artist Taryn Simon, in her 2009 project Contraband, photographs items illegally imported into the U.S. and seized by the authorities, and Contraband meets Iversen's definition; it too is performed to instruction. The project is carried out in a prescribed manner and over a prescribed time span (5 days at JFK airport, New York). The 1,075 contraband items are each presented in the same way: simple, clear and decontextualised, as though the project were a documentation of museum objects. In contrast to Simon's earlier project, the text heavy American Index of the Hidden and Unfamiliar (2007-8), in Contraband there is little text and the photographs themselves constitute the inventory, a list that takes its order from the performative nature of the work. The objects are grouped into sets, such as: Branding, Tiffany And Co. (Counterfeit); Fitness DVD's (Pirated); Potatoes (Prohibited); U.S. Currency (Incidental To Arrest). These categories form a descriptive list, and, as will be argued in relation to the archive list, one that forms the plot. Importantly, as Hans Ulrich Obrist argues, in his 'Ever Airport: Notes on Taryn Simon's Contraband', a foreword to the book of the project, the photographs too are 'something approaching the approximately impersonal and administrative form of the list' (2010, 9). He continues:

the photographs and texts of Simon's Contraband reveal disorder and chance within the strictures of a system determined by absolute order and control [.... Simon's images and lists embrace both order and disorder, and open up a third space within the cracks of these forms of control. (ibid.)

The 'administrative form of the list' immediately introduces the idea of recordkeeping and archival practices. Simon's work indeed leads us to the 'order and disorder' of the archive: structured, archival disorder that can materialise through the structure of a non-structure. The third space that Obrist refers to is that of original order.

Fiona Banner's All the World's Fighter Planes 2004 is a visual directory of fighter aircraft, but, unlike the museum-like photographs of Simon's Contraband, she uses found images, roughly cut from newspaper articles on war and conflict, often with some fragments of residual text showing. The planes are listed on the front and back covers of the publication, acting as a very visible index to this classificatory work and 
highlighting the artist's long-term engagement with language. Stephen Bury (2005, para. 4), in his review of the book, recalls Banner stating at the book launch that it is 'all about nature', with aircraft names such as albatross, hornet, hind, cayuse, eagle, cougar, lion cub, cheetah, aardvark, nighthawk, making references to bird watcher manuals and such like. There is in a strong connection and allusion in Banner's book to early photographic classification used within the natural sciences.

\section{Discontinuities}

The notion of 'original order', with its unexpected connections, relationships and discontinuities that provide evidence of particular organisational and operational habits, has confluence with Foucault's views on modern historical analysis, through which, 'unities, totalities, series, relations' can be defined $(2002,7)$. In relation to this theoretical framework, the archival list is of great practical importance: it is not only significant as a finding aid, but as an insurance policy against the misfiling of objects, against the loss of evidence of the methodological mechanisms of collection and use. Modern historical research centres on the search for new avenues of knowledge and it is not concerned with chronologies, but with the analysis of concepts. A chronological or conceptual arrangement of the archive would not accommodate different types of historical analysis, hence the Dutch Manual's concern for tight recordkeeping: a preservation of discontinuities. In The Archaeology of Knowledge, Foucault $(2002,9)$ perceives a major turn in historical research. He describes the 'discontinuous' as alien to classical historians and states:

For history in its classical form, the discontinuous was both the given and the unthinkable: the raw material of history, which presented itself in the form of dispersed events - decisions, accidents, initiatives, discoveries; the material, which through analysis, had to be rearranged, reduced, effaced in order to reveal the continuity of events. Discontinuity was the stigma of temporal dislocation that it was the historian's task to remove from history.

Foucault goes on to describe how discontinuity has become a basic element of historical analysis and deems it 'both an instrument and an object of research'. He maintains that discontinuity must cease to be seen as hindrance, but instead it must become a 'working concept' $(2002,10)$. 'He argues strongly for a 'systematic erasure of all given unities' and a return to a specificity of occurrence that recovers discontinuities. He claims that that the removal of 'natural, immediate, universal unities' can allow unexpected unities to occur or to be formulated (Foucault 2002, 31 2). Archival ordering not only presents and preserves natural discontinuities amongst objects, but the neutrality of its description and classification affords other discontinuities that may lie outside of standard cultural categorisations. 
Terry Cook (2001, 6-7), as part of his rationale for the 'postmodernisation' of archives, cites Foucault and Derrida, with their respective ideas on understanding and dismantling 'systems of organised knowledge'. He centres his attention on broad themes of poststructuralism, such as reading through and behind text, and with Derrida's Archive Fever (1998) cited as the text that spawned a wave of studies on the archive's significance in society. Cook considers the implications of postmodernism for archivists, arguing that they must 're-think their discipline and practice' in a postmodern world $(2001,3)$. In taking this approach, he gives little attention to the part researchers play in the discovery of context through interrelationships, their role in 'the questioning of the document' (Foucault 2002, 6 [original italics]), or to the role that archivists have traditionally played in affording this questioning. Cook calls for a change in archival practices to one that moves away from the 'guardianship' of the document into a mode of 'actively shaping collective (or social) memory' $(2001,4)$. He describes a world where '[n]othing is neutral. Nothing is impartial. Nothing is objective' $(2001,7)$. However true this statement may be, the conventional neutrality, impartiality and objectivity of the archivist, taken together with the concept of original order, should preclude active interpretation or shaping of memory: the archivist's task is to document and preserve what Foucault $(2002,9)$ terms the 'raw material of history'. In Cook's essay, the role of archivist and that of researcher become somewhat confused; the 'postmodernisation' of the archivist that he calls for contradicts Foucault's rejection of the formation of 'cultural totalities' $(2002,17)$, and his call for 'rigorous but unreflected relations' $(2002,15)$.

Liam Young perceives the list as a highly visual method of spatial organisation. He argues, 'Lists draw things together and put them in relation to one another - as visual forms of information, they tell us things that were previously unavailable. Connections are forged and relations become traceable' $(2013,506)$. He continues on this theme, 'A form such as the list forges units, relations, and caesuras via other visual means - borders, columns, numbers, lines, words, commas etc. — and as a result helps us to see and to imagine strange resonances between words, things, data, and people that might otherwise escape our grasp' (2014, para. 8) But as well as being a spatial form, a system of interstitial writing that in the archive describes a form of interstitial storage, a list is also a method of keeping time and of temporalisation. Young's 'units, relations, and caesuras' participate in the formation of knowledge through an alignment of information that may not be chronological: a photograph pinned to a letter from a different time period or a document that has clearly been removed from one file and deposited in another represent temporal deviations that may be significant in terms of evidence of prior use.

\section{The narrative pause}

Vismann (2008, 6-7) recounts how lists dating back to the Babylonian Empire of the third millennium $\mathrm{BC}$ were misunderstood as narrative texts that could not be 
translated. In 1935 they were finally accepted as non-syntactical writing, 'administrative notes rather than epic texts', and later translated as such, providing valuable evidence of the organisation and governance of day-to-day life. Ernst informs us that the old English word tellan comes from the old German, meaning 'to put in order', and that this applies both to narration and to counting $(2013,148)$. He describes how Homer's Iliad contains a list of ships, a 'narrative pause' (a term in narrative theory generally applied to description). He quotes D.P. Fowler $(1991,25)$ on the narrative pause, who states, 'The plot does not advance, but something is described.'

Ernst argues:

To tell as a transitive verb means "to count things." When all sensual dimensions are quantifiable, even the temporal resolution, telling gets liberated from the narrative grip - a media-archaeological amnesia of cultural techniques like that of the early medieval annales, sequential notations of temporal events with no metahistorical, narrative prefiguration. We get a glimpse of a way of processing cultural experience that does not need stories (not yet? not any more?). Modern historians, though, are obliged not just to order data as in antiquaries but also to propose models of relations between them, to interpret plausible connections between events (2013, 149 [original italics]).

Ernst concurs with Foucault regarding the nature of modern historical research and reporting, but he is also positioning the non-narrative processing of cultural experience in the context of network storage and retrieval systems. As Liam Young explains, 'calculation biases [of non-narrative modes of telling] are far better equipped to guide our understanding of the code-based logic of contemporary network society' (2014, para. 7). As well as demonstrating the organisation and clustering of data within networks, Ernst's example represents a typical arrangement in the archive, where pockets of chronological data sit inside other less time-ordered (though static) structures. Paradoxically, it is through the stasis of the archive that the plot clearly does advance: the objects in the archive, whilst still not constituting a narrative, inform (tell) the plot through a diachronic progression of time, through a multiplicity of pauses.

The description of a single image is itself a fine example of narrative pause: it parallels the camera shutter as a pausing of action, the capture and embodiment of a moment in time. There is no time within still images except for the fraction of a second that the shutter is open and the duration of the event is defined by the wider series of images and descriptions. Take, for example, the following extract from a catalogue list for the Harry Price archives, Senate House Library, University of London: 
HPG/1/8 Fire Walking

1935-1946

Photographs of Harry Price's investigations into fire-walking and experiments with Kuda Bux and Ahmed Hussain at Carshalton, Surrey and Alexandria Palace, London. Includes photographs of tests with both firewalkers and the BBC transmission of Hussain's fire-walk in 1937, along with photographs of fire-walks in other countries.

\section{HPG/1/8/3 Ahmed Hussein: First Test}

1937

Photographs from the first fire-walking test conducted with Cawnpore Muslim, Ahmed Hussain at Carshalton, Surrey (7 April 1937), including the following:

i. Upper body studio photograph of Ahmed Hussain (2 copies) [1122, 1123]

ii. Photograph of nurses washing Ahmed Hussain's feet prior to the fire-walk

iii. Photograph of nurses washing Ahmed Hussain's feet prior to the fire-walk, different shot from above

iv. Upper body photograph of Harry Price, C.E.M.Joad, Ahmed Hussain and O.K.De Silva (Hussain's manager), with Price and De Silva pointing, possibly at fire trench

v. Photograph of back view of Ahmed Hussain praying just before his first fire-walk

vi. Photograph of Dr Parnett and Dr Newcomb examining Hussain's feet after the first walk

vii. Photograph of Dr Parnett and Dr Newcomb examining Hussain's feet after the first walk, different angle from above

viii. Photograph of Dr Parnett taking temperature of Hussain's feet prior to walking

ix. Photograph of Dr Parnett and Dr Newcomb taking temperature at Hussain's feet before walking

x. Photograph of the raking of the fire trench just before walking

xi. Photograph of man raking the fire ready before walking

xii. Photograph of back view of Hussain walking over trench

xiii. Photograph of Mr Hawkins (of Cambridge Instruments) taking the temperature of the fire trench

xiv. Photograph of Mrs Dribbel, Harry Price, C.E.M.Joad, Ahmed Hussain and O.K.De Silva standing by fire trench

xv. Photograph of Reggie Adcock walking over the fire trench (He was unburnt) 
The time anomalies within this list of photographs can be clearly identified. The short descriptions, their separation emphasised by of the absence of temporal continuity, describe the event in a filmic way, as cuts and flashbacks highlight the action. Ernst (2013, 154) describes how events are revealed in the Bayeux Tapestry as a 'precinematic form of cutting that has often been added to film or comic strips, with abrupt changes in pace, jumps in time, and flashbacks.' He continues, 'Physically though, film puts sequences one after the other on a celluloid reel-just as on the Bayeux tapestry.' The Fire Walking photos, unlike either film images or the Bayeux Tapestry, are not physically connected, but placed loose in a file; their sequence is determined and they are connected by the numbered catalogue list and by their upper level description, in this case, the title and the two lines introducing the list.

In his film La Jetée (1962), Chris Marker approaches time in a way that must be understood through a comparative processing of situations and relations that requires, and in turn affords, a more profound understanding of the precarious temporality of the event. La Jetée is a made up of a limited set of still images (with the exception of a brief moment of movement) preserved in a particular order. Like the Fire Walking list, it is distinct from a narrative in that its elements are contiguous, but not chronologically consecutive or interpolated, temporal but not linear. Both these image sets must be read through something other than a narrative gaze. Ernst $(2004,264)$ quotes Roger Odin (in Gaudreault: 1990, 72), who writes in relation to La Jetée: 'The absence of reproduction of movement $[. .$.$] tends to block narrativity, since the lack of$ movement means that there is no before / after opposition within each shot. The [effect of] narrativity can only be derived from the sequence of shots, that is, from montage' [original italics]. Doubt is placed upon La Jetée as a narrative form, although the film clearly and famously has a story to tell. In clarifying the understanding of the word 'narrative', there is a simple distinction to be made between the terms 'story' and 'narrative', although they are often perceived as interchangeable. A 'story' is defined as an 'event or sequence of events' that make up an action (Ryan: 2008, 344). This is relatively acceptable in terms of how one views sets of archived photographs, although inside and outside the archive description writing and list making are methods of recording, not storytelling. A 'narrative', however, involves a combination of story and discourse: 'an ability to evoke stories in the mind' (Ryan: 2008, 347). It is this combination that is most problematic in terms of the archived image as a site of evidence, as it involves imagination, speculation, fantasy and fabulation to create a storyline outside of the image or the sequence itself. As Ernst argues (2013, 153 [original italics]), 'Description is at odds with narration.'

Description is perceived as a low form of writing: it experiences, as D.P. Fowler puts it, 'poor relation status'. But Fowler calls for its celebration, and he argues, 'the more radical move is to free description from the chains of slavery and to give it true autonomy' (1991, 26-27). He cites nouveau romancier Alain Robbe-Grillet as a proponent of this approach, who states "instead of this universe of "significations" (psychological, social, functional), one must try to construct a world more solid, more 
immediate' (quoted in Halsall 1988, 27 [original italics]). The Nouveau Roman writers of 1950s and 1960s France, such as Robbe-Grillet and Georges Perec, turned away from contemporary existentialist writing and used descriptive techniques to afford an equality of denotation that meant that nothing was signified at all. The archive photograph is placed outside of the system of signs that is usually considered in discussions of photographic representation and placed with the organisational system of the archive. Accordingly, the archive catalogue becomes the sign system for the archived photograph.

\section{Coda}

The responsibility of the archive is primarily one of custodial care and preservation. It is a space that demands stasis in order to justify its existence, yet it still emerges as a powerful, productive and temporally dynamic space. Jussi Parikka sees archival notions of storage and freezing time as 'an index to a way to understand time, rethink time as something that is at the core of the wider media-archaeological process' $(2013,12)$. The catalogue list presents a way in to the understanding of the timecritical space of the archive, as it travels from 'the general to the specific' (ISAD(G) 2000,12 ), beginning with the description of the fonds and ending in the description of the single object. The temporal configuration of the archive follows this structure, as it too moves from general to specific time, from event to situation.

Photography is a spatiotemporally complex technical medium. The photograph represents the capture and embodiment of a short duration of time and a preservation of this time for future use. In this respect, it becomes an apt metaphor for the static and preservatory nature of the archive itself. The archive's management and the reader's processing of cultural information through image description and list could be seen as being situated on the borders, the crossroads of the experiential, between image and text. Questions arise about how much is delivered by description in terms of information (archive-approved) and terms of in terms of sensation (not archiveapproved). One might even ask how far and in what departments does description perform better than image, and to what extent is the image simply a descriptive form, a method of indexing in itself. After all, the photograph has been identified as 'narrative pause', on a par with lists and annals. The technique of image description is readily distinguishable from hermeneutical analysis and the argument here is not about the sensational nature of either the photographic image or the description. Rather, it is about a form of information management that offers a different way to write and to read the image and to expose the temporal development of the image set. To return to the notion of the catalogue as a 'machine for thinking', it is hoped that whilst maintaining the structural discourse of the archive, there is opportunity for complex thought around images and image time. 


\section{References}

Banner, F. (2004) All the World's Fighter Planes 2004, London: Vanity Press

Belknap, R. (2004) List: the Uses and Pleasures of Cataloguing: Contract under Classification of Chaos, New Haven, CT: Yale University Press

Burgin, V. (2011) Parallel Texts: Interviews and Interventions about Art, London: Reaktion Books Ltd

Bury, S. (2004) 'All the World's Fighter Planes', Art Monthly, [online], 287. Available at http://www.fionabanner.com/words/artmonth.htm. Accessed 21 April 2015

Cook, T. (2001) 'Archival Science and Postmodernism: New Formulations for Old Concepts', Archival Science, 1, 3-24

Derrida, J. (1998) Archive Fever: a Freudian Impression, Chicago: University of Chicago Press

Ellis, J. (1993) Keeping Archives, Port Melbourne, Victoria, Australia: D. W. Thorpe

Ernst, W. (2001) 'Art of the Archive', in C. Weber (ed) Art. Archive: New Works on Historical Holdings, Cologne: Verlag der Buchhandlung Walther König

Ernst, W. (2002) 'Archive in Transition', in B. Von Bismark, H.-P. Feldmann, H.U. Obrist, D. Stoller, and U. Wuggenig (eds) Interarchive, Köln: Verlag der Buchhandlung

Ernst, W. (2004) 'Towards an Archive for Visual Concepts', in T. Elsaesser (ed) Harun Farocki: Working on the Sight-Lines, Amsterdam: Amsterdam University Press

Ernst, W. (2013) Digital Memory and the Archive, (ed and intro J. Parikka), Minneapolis: University of Minnesota

Flusser, V. (2013) 'Our Images', in S. Zielinski (ed) Post-history, Minneapolis: Univocal Publishing

Foucault, M. (2002) The Archaeology of Knowledge, London: Routledge

Fowler, D. P. (1991) 'Narrate and Describe: the Problem of Ekphrasis', Journal of Roman Studies, 81, 25-35 
Gaudreault, A. (1990) 'Film, Narrative, Narration: the Cinema of the Lumière Brothers', in T. Elsaesser (ed), Early Cinema: Space, Frame, Narrative, London: British Film Instititute

Keller, C. (ed) (2008) Brought to Light: Photography and the Invisible, 18401900, San Francisco: San Francisco Museum of Modern Art / Yale University Press

Halsall, A. (1988) '"La Transition", Description et Ambiguités NarritivoDiscursives dans "Victoire' de William Faulkner', in J Bessière, (ed) L'Ordre du Descriptif, (n.2), Paris: PU de France, 159-72

Hood, C. C. \& Margetts, H. Z. (2007) The Tools of Government in the Digital Age, Basingstoke: Palgrave MacMillan

ISAD(G) (2000) General International Standard Archival Description, 2nd edition, Ottawa: International Council on Archives

Iversen, M. (2010) 'Auto-Maticity: Ruscha and Performative Photography', in D. Costello \& M.E. Iversen (eds), Photography after Conceptual Art, Chichester: Wiley-Blackwell

Jäger, J. (2001) 'Photography: a Means of Surveillance? Judicial Photography, 1850 to 1900', Crime, History \& Societies [online], 5. Available at http://chs.revues.org/1056. Accessed 5 December 2014

La Jetée (1962) Directed by Chris Marker [Film], France: Argos Films

Ketelaar, E. (1996) 'Archival Theory and the Dutch Manual', Archivaria, 41, $31-40$

Krajewski, M. (2011) Paper Machines: About Cards and Catalogs, 1548-1929, Massachusetts: Massachusetts Institute of Technology

Magnani, G. (1990) 'Ordering Procedures: Photography in Recent German Art', Arts Magazine, 64, 78-83

Manoff, M. (2004) 'Theories of the Archive from Across the Disciplines', Libraries and the Academy [online], 41. Available at http://dspace.mit.edu/bitstream/handle/1721.1/35687/4.1manoff.pdf.

Accessed 27 March 2014

Obrist, H. U. (2010) Introduction, in T. Simon, Contraband, Göttingen: Steidl 
Parikka, J. (2012) What is Media Archaeology? Cambridge, UK: Polity Press

Parikka, J. (2013) 'Archival Media Theory: an Introduction to Wolfgang Ernst's Media Archaeology', in W. Ernst (J. Parikka ed), Digital Memory and the Archive, Minneapolis: University of Minnesota

Ryan, M.-L. (2008) 'Narrative', in D. Herman, M. Jahn and M.-L. Ryan, (eds), Routledge Encyclopedia of Narrative Theory, Abingdon: Routledge

Sekula, A. (1982) 'On the Invention of Photographic Meaning', in V. Burgin (ed) Thinking Photography. Basingstoke: Macmillan

Sekula, A. (1984) Photography Against the Grain: Essays and Photoworks 1973-1983, Halifax, Nova Scotia: The press of the Nova Scotia College of Art and Design

Sekula, A. (1986) 'The Body and the Archive’, October, 39, 3-64

Sekula, A. (2003) 'Reading an Archive: Photography Between Labour and Capital', in L. Wells (ed), The Photography Reader, London: Routledge

Simon, T. (2010) Contraband, Göttingen: Steidl

Van Dijck, J. (2007) Mediated Memories in the Digital Age, Stanford, California: Stanford University Press

Vestberg, N. L. (2013) 'Ordering, Searching, Finding', Journal of Visual Culture, 12, 472-489

Vismann, C. (2008) Files: Law, Media and Technology, Stanford, California: Stanford University Press

Young, L. (2013) 'Un-Black Boxing the List: Knowledge, Materiality, and Form', Canadian Journal of Communication, 38, 497-516

Young, L. (2014) 'On Lists and Networks: an Archaeology of Form', Amodern [Online], 2. Available at http://amodern.net/article/on-lists-and-networks/. Accessed 20 November 2014 
Jane Birkin is an artist and independent scholar. She is a researcher and visiting lecturer at Winchester School of Art, University of Southampton, where she recently completed her $\mathrm{PhD}$. The locus of her practice-based research is the archive, and she is specifically concerned with archival description techniques that define and manage the photographic image.

Email: J.A.Birkin@ soton.ac.uk 